\title{
Features of the New Type Global Recession
}

\author{
Alexander Lyakin ${ }^{1, *}$ \\ St.Petersburg State University, Faculty of Economics. 62, Chaikovskogo street, St Petersburg, \\ 191194, Russia
}

\begin{abstract}
Research background: The increasing global economic decrease that got the name of Great Lockdown had world pandemic as its trigger. It is already obvious that by its depth, breadth and the number of economics included this recession can be compared to the Great Depression. Shocks nature influences a lot on the structural changes during the recession. The tertiary sector industries, which development is determined by globalization and that are typical for post-industrial economies have the heaviest losses. Now it is impossible to predict are the de-globalization processes permanent or just temporary and which changes in sectoral structure will stay with us after the COVID-19 pandemic. The period of sharp drop is finishing now and it's obvious that the specific nature of current recession will reveal itself during the market adjustment to the new conditions.

Purpose of the article: is to highlight the specific features of recession caused by COVID-19 pandemic, distinguishing it from the previous global recessions.

Methods: this article research is based on comparative analysis of main macroeconomic variables trends during the global recessions.

Findings \& Value added: Current global recession specific features highlited in this article are:

industries with a high share of employment are subject to the greatest compression;

the economic recession took its origin as a result of the supply shock, and it has a clearly defined industry specifics. The growing uncertainty is limiting the recovery growth potential.;

Keynesian measures of countercyclical regulation appeared to be ineffective during the release restrictions phase.
\end{abstract}

Keywords: Great Lockdown, structural changes, countercyclical regulation, deglobalization

JEL Classification: E32; E63; F44; F62

\footnotetext{
${ }^{*}$ Corresponding author: $\underline{\text { a.lyakin } @ \text { spbu.ru }}$
} 


\section{Introduction}

The contraction of the world economy in the second quarter of 2020 may become the beginning of a global economic crisis comparable to - or greater than - the Great Depression. The extent of decline recorded by results of the first six months of the year in all developed countries has already surpassed the Great Recession, and, with all due caution, the World Bank and IMF estimate the assumed slump in production to be the gravest in the new century. The new crisis was triggered by the event of non-economic nature, in fact, by a global pandemic, and to be more precise - the actions of the Governments aimed at limiting its spread. However, the theory of cyclical oscillations prevailing in the economic science today treats the cycle as a response of the economic system to an external shock disturbing its balance and its further recovery through changes in the employment, prices, interest and other economic variables. The nature of the impulse that has deranged the emergent conditions is not of fundamental importance; what is important is that the productivity factor changes as a result.

The processes unfolding in the world economy have already got the name of a perfect storm. The current crisis is not of Keynesian nature. The output reduction is caused not by the aggregate demand changes, but by the external constraints of non-market nature. The sanitary and hygiene requirements change the productivity in a number of economic sectors - due to the increasing costs (additional equipment, individual means of protection and hygiene) and owing to the forced reduction of the overall scope of activities (seating requirements for passengers and spectators with observance of social distance, limitation of maximum allowable number of service consumers, etc.). The Governments' attempts to compensate the constrained demand through budget-funded payments partially solve the social problems, but provide no ways to restore the economy. The remaining core objective is to lift the bans on economic activity. Comprehension of the fact that the quarantine generates heavier losses than the pandemic, including those measured in terms of human lives, is now becoming shared. The rate of recovery after lifting the bans will depend crucially on the adequacy of stabilization policies in relation to the economic conditions that have taken shape during the quarantine. However, it is important to note that the current crisis has a number of quite specific features that complicate prognostication of its course and require special measures in the economic policy.

\section{Methods}

The triggers of the global crises of the present and past centuries used to be demand shocks. The burst of market bubbles, along with the changes in relative prices and the surge of interest rates resulted in contraction of aggregate demand, capital revaluation, loss of assets and corporate balance problems. [1] In these conditions, the fiscal and monetary-policy measures were aimed at stimulating household expenses and compensating the falling corporate demand. For all the peculiarities of the Great Recession of 2007-2009, it developed under the same scenario.

The 2020 decline in production was caused by the supply crisis which was provoked by the event beyond the economic sphere. The quarantine introduced in the majority of countries affected seriously not only on the output volume, but also its structure; it required technological changes, had an impact on capital productivity and disbursements, on relative prices. The primary shock peculiarities manifest themselves through the scale of the recession and the forms of subsequent adaptation of the economy to the new conditions. So far, the sufficient data on the ongoing processes are not available; however, it is obvious, already at this stage, that the economic recovery will extend for a long time and will take a different shape than at the time following the Great Recession of 2007-2009. 
At present, research is primarily aimed at identifying the scale of recession caused by the quarantine, its impact on the financial markets, assessment of governmental measures to address the social problems and compensation of the shrinking demand. Yet, it is necessary, already now, to highlight a number of significant features that distinguish the current decline from the previous crises.

Comparative analysis of consistency and coherence of crisis processes during the " great lockdown» and the global recession before it highlighted specific features of current recession and potential areas of its development. Regression analysis between scale of disease and national economic level of development was made in order to uncover the epicenter of crisis. Structural problems are distinguished from fluctuations in market capitalization by field of activity.

The fact that the depression was caused not by the demand shock, but by the supply crisis is a crucial factor for the extent of economic losses and efficiency of standard forms of stabilization policy, as well as for the potential dynamics of economic recovery. The combination of these features determines the potential sequence of events in the course of economic recovery as well as conditions the extent and focus of changes in the sectoral structure.

\section{Results}

The crisis that has already taken shape was originally evaluated by the business and expert community predominantly as a protracted, L-shaped, with a high volatility of recovery growth. [2] The forecasts regarding the scale of global GDP losses in 2020 are consistently revised towards the worse, but the first incoming data show that the primary projections were made under an optimistic scenario. The real decline in the first half of the year proved to be more drastic than the projected one (Table 1).

Table 1. Projections of growth/decline of the world economy in 2020 (\%GDP)

\begin{tabular}{|c|c|c|c|c|c|c|}
\hline \multirow{2}{*}{\begin{tabular}{|l|} 
Source of forecast \\
Month of publication \\
\end{tabular}} & \multicolumn{3}{|c|}{ IMF } & \multirow{2}{*}{\begin{tabular}{|l|} 
WB \\
June \\
\end{tabular}} & \multirow{2}{*}{\begin{tabular}{|l|} 
OECD \\
August \\
\end{tabular}} & \multirow{2}{*}{ 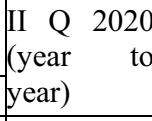 } \\
\hline & January & April & June & & & \\
\hline World & 3,3 & -3 & $-4,9$ & $-5,2$ & $-4,5$ & - \\
\hline Advanced economies & 1,6 & $-6,1$ & -8 & $-7,0$ & - & - \\
\hline USA & 2 & $-5,9$ & -8 & $-6,1$ & $-3,8$ & $-9,1$ \\
\hline Euro Area & 1,3 & $-7,5$ & $-10,2$ & $-9,1$ & $-7,9$ & $-11,8$ \\
\hline $\begin{array}{l}\text { Emerging market and developing } \\
\text { economies }\end{array}$ & 4,4 & -1 & -3 & $-2,5$ & - & - \\
\hline China & 6 & 1,2 & 1 & 1,0 & 1,8 & 3,2 \\
\hline India & 5,8 & 1,9 & $-4,5$ & $-3,2$ & $-10,2$ & $-23,9$ \\
\hline Russia & 1,9 & $-5,5$ & $-6,6$ & $-6,0$ & $-7,3$ & -8 \\
\hline
\end{tabular}

If the morbidity rate in autumn goes up, then the quarantine measures are unlikely to be as strict as in spring, but this time the economic recovery is constrained by the falling demand. At the same time, increased supply in the previous activity lines is so far constrained. In virtue of the recession grounds specificity, its shape is different from the course of previous recession periods.

I. The current recession has affected primarily the developed economies. Although the pandemic enveloped the whole world, the morbidity surge began in the rich countries at the first stage, affecting the upper-income population groups and the economic sectors that catered for their consumption.

Simple linear regression shows this relation: 
where:

$$
\ln C O V I D-19=C+\ln G D P_{P P P}+\varepsilon
$$

COVID - 19 incidence per 100,000 of the population,

$\ln G D P_{P P P} \quad$ GDP per capita in purchasing power parity terms,

$\varepsilon \quad$ regression equation error.

Regression was calculated for two dates: April 10 and August 31. The 2018 GDP percapita data were provided by the World Bank; the COVID-19 incidence data were provided by Johns Hopkins University.

On April 10, the regression equation was as follows:

$$
\operatorname{lnCOVID}-19=-11,2728 * * *+1,64666 \ln G D P_{P P P} * * *+\varepsilon
$$

$$
(0,875343) \quad(0,0923006)
$$

$R^{2}=0,655$, standard errors are specified in brackets, $p$-value $<0,0001 * * *$

Model: OLS, using observations: 170

Dependent variable: $\ln C O V I D-19$

$\begin{array}{lclc}\text { Mean dependent var } & 4,225878 & \text { S.D. dependent var } & 2,370889 \\ \text { Sum squared resid } & 328,2007 & \text { S.E. of regression } & 1,397704 \\ \text { R-squared } & 0,654514 & \text { Adjusted R-squared } & 0,652458 \\ \text { F(1, 168) } & 318,2717 & \text { P-value(F) } & 1,28 \mathrm{e}-40 \\ \text { Log-likelihood } & -297,1348 & \text { Akaike criterion } & 598,2697 \\ \text { Schwarz criterion } & 604,5413 & \text { Hannan-Quinn } & 600,8146\end{array}$

The regression equation calculated as of August 31 no longer shows expressed dependence of morbidity on the level of economic development.

$$
\operatorname{lnCOVID}-19=-0,888469 * * *+0,82847 \ln G D P_{P P P} * * *+\varepsilon
$$

\section{$R 2-0,275444$}

$$
(0,983139) \quad(0,103667)
$$

The relationship between welfare and morbidity is enrooted in the forms of consumption and social behaviour inherent in rich countries and high-income groups. It is in the developed countries that the share of services in the structure of GDP is high, including those assuming their shared consumption (education, culture, public transport, etc.). In addition, the development of recreational sector, especially tourism services, contributes to rapid spread of the disease, its transfer between countries and regions. Thus, the relationship between the air passenger traffic density and the duration of the epidemic up to its peak was proved in the paper by Aronov, Maksimova, Galkina. [3] As to the poor countries, the epidemic comes there later, but it spreads quickly due to overcrowding, poor living conditions, poor domestic hygiene, poor-quality medicine. Therefore, after the first outbreak in wealthy countries, the incidence got increasing in South Asia and Latin America.

As a result of grand-scale economic decline in the prosperous countries and a significant slowdown in China, the 2020 recession will lead to a decline in the global GDP generally, for the first time after the Second World War. And given the changes in the quality of national accounts statistics, along with the breadth of their global coverage - perhaps for the first time ever, as a matter of fact.

The national economy decline rates correlate with its structure. The most vulnerable are advanced economies, services oriented and «experience economy».

The output decline as a result of production cease is the recession trigger, but it is only the beginning of recession. The contraction of demand has unusual form, because the consumption of high income segment is limited by the epidemic control measures.

Extraordinary costs during the stabilization policies implementation pose a threat of crisis for government finance system and slow recovery after it. 


\section{Discussion}

The cyclical development theories have long been based on two different principles. The cycle was regarded either as a result of internal economic processes causing fluctuations in growth rates (this approach has a long history from late 19 century and ending with $\mathrm{H}$. Minsky's theory [4] - or as a result of external shocks changing the efficiency of production factors and pushing the economy out of the balanced state. The subsequent adaptation to the new conditions leads to market fluctuations and unsteady growth. Such models, following the works of F. Kydland and E. Prescott [5.6], have become a mainstream in cycle analysis. The current crisis started with a shock in supply, not a financial crisis or liquidity shortage, or contracted demand. The output decline in the real sector has affected a wide range of industries due to the enforced restrictions. It is important to understand, in addition to the short-term effect of the negative impulse, the gravity of long-term consequences caused by such shocks. The review of essays on the impact of epidemics, natural disasters, terrorist acts, and other catastrophes on financial markets, governmental decisions in economics, etc. shows that the long-term impact of such events on insurance and the price of capital is substantial, and the consequences are difficult to predict. [7]

At the same time, the process is developing so impetuously that the national accounts statistics cannot so far reflect it adequately. The data on GDP dynamics and production accounts are just becoming available. Accordingly, the quantitative analysis is based, in the first place, on the financial market information. The first attempt to assess the structural variability of the decline by economic industries, made by McKinsey, was based on the evaluation of market capitalization losses by sectors. The stock market collapse in the third decade of March was accounted for by the crash in stock prices of airlines (-40\%), oil and gas companies $(-34 \%)$, banks $(-25 \%)$, insurance companies $(-23 \%)$, while the smallest losses were incurred by pharmaceutical firms, IT and retail companies. [2, p.71] Similarly, Mazur, Dang, Vega considering the March drop in the financial markets, single out a group of corporations that increased their profits (gas, food, healthcare, software), against a group of loser corporations (oil, real estate, entertainment, hotel catering); it is important in this aspect that impairment of the securities value is accompanied by the growing volatility [8]. The growing structural problems during the lockdown are highlighted in the article by Sharif A., Aloui C., Yarovaya L. Using the wavelet coherence method and Granger's wavelet-based causality tests, the authors show that COVID-19 leads to a drop in oil prices, which in turn causes increasing uncertainty and geopolitical risks that are more significant than the lockdown.[9] Caggiano, Castelnuovo and Kima estimated the 2020 losses of the global industrial production caused by financial uncertainty inherent in the pandemic to be 14\% [10] The stock market profitability analysis based on the data collected for 77 countries showed a significant negative impact of the restrictive measures on the economic activity, along with some indirect positive effect in terms of reduction of morbidity; it highlighted as well the positive impact of the governmental support measures. [11]

The lack of statistical information needed to assess the losses at the first, most acute, phase of the recession induced the analysts to look for indicators that work with a short delay and make it possible to evaluate the output decline scale properly. Cargo transportation volume, number of payments and average purchase amount may be used as such. The most popular method enabling the researchers to make a rapid estimate of potential losses and to assess the efficiency of government support measures in the given situation is assessment of energy consumption dynamics adjusted for temperature variations and the calendar effect. The Swiss economics estimates show twofold GDP losses as compared with the financial crisis of 2009. [12] Similar calculations for the Italian economy, made for three selected weeks of the strict quarantine, showed a $30 \%$ loss in 
GDP, and despite the relief of measures and gradual improvement of the overall situation by the end of the first year-half, the further decline will amount to $8.5 \%$. [13]

Another method of preliminary assessment of the economic losses caused by the ban on economic activity, prior to publication of official statistics on national accounts, is the analysis of labour market data, available in a weekly and monthly format. The Swiss economy assessment shows increased unemployment rate during the quarantine period, from $3.7 \%$ to $5 \%$ in the third quarter; the share of long-term unemployment is expected to grow almost four times. [14] The uncertain prospects regarding the end of the epidemic raise the issue of potential possibility to adjust to the new life conditions. $37 \%$ of jobs in the US economy may be performed remotely, accounting for $46 \%$ of the total wages, although the remote employment opportunities vary significantly depending on the territory and industry. Applying the same job classification to other countries shows that the poorer the country, the less opportunity is available to do work from home. [15]

A number of research essays address the social consequences of the quarantine. Assessing the decisions regarding quarantine duration, with account taken of mortality rate and economic losses, Balmford, Annan, Hargreaves, Altoè, Bateman come to the conclusion on the countrywise differences in the life price. While in the USA, Italy, and Great Britain it amounted approximately to $\$ 100,000$ (without regard for potential underreporting of mortality data), it exceeded $\$ 1$ million in a number of countries. The epidemiological model used by the authors showed that a one-week delay in the introduction of the quarantine in eight countries would have increased the number of victims by half a million. [16] The downside of the social costs is meanwhile highlighted in other papers. For instance, Ward shows, by example of South Africa, that 19 death cases induced a three-week quarantine - that is in the country where 66,000 people die of tuberculosis and 43,000 are killed annually. The economic consequences in the countries with a high level of social inequality are particularly painful for the poor population. [17] The governments face a choice to be made between two options with a negative outcome. The drop in production leads to increased mortality as a result of alcoholism and suicides, while the situation may extend for a lengthy period due to the long-term structural shifts. [18]

Although the possibility of the second wave of the epidemic is quite likely, the repetition of large-scale sectoral restrictions similar to those enforced in most countries in the spring and early summer is highly improbable. The fact that the applied treatment is fraught with greater threats than the disease itself is now realized by all governments. However, the crisis ensuing from the lockdown is compared with the preceding great recession only in quantitative terms: the extent of decline in the course of the crisis-induced shock, the growth of unemployment, etc. At the same time, some qualitative differences are becoming apparent, that affect the efficiency of the stabilization policy and the potential scope of the crisis.

Since the mid-1970s, the impetus for real sector recession was provided by financial crises. Consequently, crises used to develop owing to liquidity shortfall and growth of interest rates, gradually covering all sectors of the economy. Any recession led to changes in the sectoral structure of the economy, creating more favourable environment for specific sectors, as compared to the others. To assess the intensity of structural changes, an extensive class of indices is normally used, that evaluate ongoing structural shifts. Typically, the process of structural changes, except for the case of transformational crises in post-communist countries, did not show radical acceleration during a downturn in developed economies with diversified structure. It can be assumed that the present depression will involve large-scale changes in the structure of the economy. The quantitative estimates are not yet available, since the national accounts statistics are not yet made public for all countries, being so far provisional. The calculation of structural indices 
requires production account data, preferably for four yearly quarters at least. Nevertheless, the statistical data that are already available suggest that the present crisis will cause major shifts in distribution of resources.

The current decline in output has its roots in the non-economic restrictions on operation of certain types of business - as a rule, the service sector. The economic globalization and the developed world's progression towards post-industrial economy resulted in a high-pace growth of activities relating to human development and accumulation of human capital: recreational industries (tourism, passenger transportation, hotels, catering, theatres, concerts, sports competitions, museums, exhibitions) and social sphere (education, healthcare, culture). These industries developed most rapidly in the post-industrial economies and were associated with the prospects of experience economy. Some of them are dominated by small and medium-size businesses, with concentrated employment. The quarantine boosted unemployment in these sectors, and the possibility of rapid recovery is complicated by shrinking incomes and increasing uncertainty that frustrates a significant share of people employed in rich economies. According to the OECD, the sectors affected most dramatically in the economy of G20 countries in 2020 are: Events \& listings - 37.7\%; Travel - 22.4\%; Performing arts - 20.4\%; Dining guides - 13.7\%; Hotels \& accommodations $-12.7 \% \dagger$. These are the areas where job expectations happened to be the worst, with a drop in April down to: Accommodation "-."78.7\%; Food \& drink services ""55.6\%; Travel services “-"47.9. And although the indices almost doubled by August, they remain much worrisome. The overall unemployment rate in the advanced economies in 2020 has already reached $8.3 \%$, reaching the figures of 2010 , while the recession is still underway.

The preservation of high uncertainty, as to the economic processes development trends, constrains the possibility of appearance of potential growth points. Even the deliverance from the current epidemic as a result of vaccination is likely to retain the apprehensive attitude - expectation of potential threat of new outbreaks, and changes in technologies will be required, to start with social distance requirements and, consequently, the fill rate of theatres, museums, restaurants, aircrafts, etc. All this, in turn, leads to higher costs and changes in relative prices. The rising uncertainty about the future development pathway slows down potential investments, while the changes in relative prices will require a period of adjustment to the new conditions. At least these two circumstances, even in case of a favourable scenario of epidemiological situation, will not allow to restore the pre-crisis output quickly and to shift to recovery growth under a V-shape trajectory.

The shrinkage of demand during the quarantine period outpaces the income drop. The household savings growth during the decline phase usually takes place as a response to uncertainty about one's future employment and income. The savings under the present recession are growing within two channels. In addition to getting secured against potential adverse events, most of the savings prove to be forced. [19] The high-income group of the population found itself limited in habitual consumption and is thus forced to save money. The restrictions on tourist trips, theatres, restaurants, gyms and other forms of leisure make the high-income groups reduce their current spending. However, unlike the deferred demand for durable goods that will be compensated when the items become available, the services that failed to be consumed will constitute a net loss of output. In addition, whereas the financial losses of the rich consumers' service providers are partially compensated by government programmes, as well as the respective drop in demand for their services, it is impossible to stimulate the demand of high-income population groups under the imposed

\footnotetext{
† https://www.oecd.org/economic-outlook/

* https://www.imf.org/external/datamapper/lur@weo/oemdc/advec/weoworld
} 
restrictions. Moreover, if the restrictive measures remain in force for a sufficiently lengthy period, then the resumption of previous lifestyles, or the very need to preserve the former infrastructure, may be called into question. The wave of bankruptcies in the service sector is so far constrained by the government guarantees, subsidies and preferential lending programmes. Cessation of these programmes, even in case of exclusion of the threat of new quarantines and spates of disease, will serve as additional grounds for economic contraction.

The stabilization policy pursued throughout the entire global economy have required extraordinary budget investments and monetary emission. Chart 1 demonstrates the worldwide GDP decline data in the second quarter of 2020, with budget-funded expenditure under the anti-recessionary programmes. The chart shows that the scope of fiscal measures is not related to the extent of economic losses, demonstrating neither direct nor inverse dependence, at least at this stage of the crisis. However, the governmental support, both in the form of subsidies to firms and households and in the form of tax concessions, has resulted in the growing budget deficit and withdrawal from the former rules and restrictions.

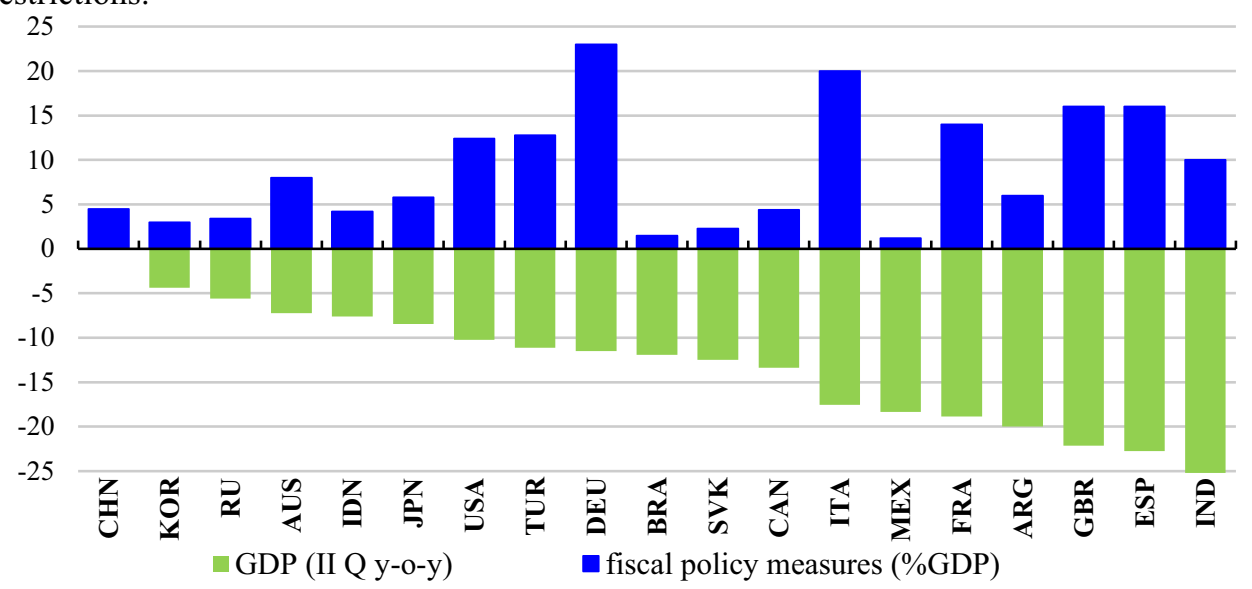

Fig.1. GDP (II Q year to year) and fiscal policy measures (\%GDP).

The budget deficit in the EU exceeded, in broad terms, the threshold value of 3\% GDP already in the first quarter, amounting to $3.8 \%$. In five countries (Belgium, Italy, Malta, Romania, France,) it exceeded 9\%. The US federal budget deficit in 2020 will amount to $16 \%$. In general, according to IMF experts' estimates, the government debt in the developed countries will amount to $122 \%$ GDP. The rapid growth of public debt is accompanied by monetary expansion in all wealthy countries and simultaneous reduction of interest rates, down to negative values. The inflation is limited by consumption drop. The result is a speculative bubble inflated in the stock market. The Standard \& Poor's 500 Index, after its March 2020 drop, has recovered to near its peak, while the real economy remains in recession. If the stock market collapses, this will prove to be an additional impetus for a slump in production and its transition to a long-term stagnation.

\section{Conclusion}

The recession brought about by the global pandemic has a number of specific features conditioned by its trigger:

1. The current recession originated in the developed economies and was conditioned by the current lifestyle of the wealthy countries' population. The economic recession took its 
origin as a result of the supply shock, and it has a clearly defined industry specifics. The growing uncertainty is limiting the recovery growth potential.

2. The reduced incomes caused by the halt of economic activity, as well as the limitation of accepted forms of consumption in high-income population groups, result in suppressed demand and impeded transition towards growth.

3. The governments' active policy to support the economy entails the rapid growth of the public debt and imbalance of the public treasury. The mass-scale monetary emission and low interest rates are inflating the financial market bubble, which creates a potential threat of a financial crisis. The transition from the crisis of supply to the demand shock - if the unfavourable scenario is realized - will lead the world economy to a long-term stagnation.

\section{References}

1. Koo, R. C. (2009). The Holy Grail of Macroeconomics: Lessons from Japan's Great Recession. Singapore: John Wiley

2. McKinsey \& Company. (July, 2020) COVID-19: Briefing materials global health and crisis response. Retrieved from: https://www.mckinsey.com/ /media/mckinsey/ business $\% 20$ functions/risk/our\%20insights/covid\%2019\%20implications $\% 20$ for $\% 20 \mathrm{~b}$ usiness/covid\%2019\%20july\%209/covid-19-facts-and-insights-july-6.pdf

3. Aronov, I.Z., Maksimova, O.V., Galkina, N.M. (2020). COVID-19 highest incidence forecast in Russia based on regression model. International Journal of Mathematical, Engineering and Management Sciences, 5(5), 812-819.

4. Minsky, H. P. (2008). Stabilizing an Unstable Economy. New York: McGraw-Hill Professional.

5. Kydland, F., Prescott E. (1982). Time to Build and Aggregate Fluctuations. Econometrica, 50 (6), 1345-1370.

6. Prescott E. (1986). Theory Ahead of Business-Cycle Measurement. CarnegieRochester Series on Public Policy, 25, 11-44.

7. Goodell J.W. (2020). COVID-19 and finance: Agendas for future research. Finance Research Letters, 53, Article Number 101512.

8. Mazur, M., Dang, M., Vega, M. (2020). COVID-19 and the march 2020 stock market crash. Evidence from S\&P1500. Finance Research Letters, in press.

9. Sharif A., Aloui C., Yarovaya, L. (2020). COVID-19 pandemic, oil prices, stock market, geopolitical risk and policy uncertainty nexus in the US economy: Fresh evidence from the wavelet-based approach. International Review of Financial Analysis, 70, Article Number UNSP101496.

10. Caggiano, G., Castelnuovo, E., Kima, R. (2020). The global effects of Covid-19induced uncertainty. Economics Letters, 194, Article Number 109392.

11. Ashraf, B.N. (2020). Economic impact of government interventions during the COVID-19 pandemic: International evidence from financial markets. Journal of Behavioral and Experimental Finance, 27, Article Number 100371.

12. Lengwiler, Y. (2020). Blacking out. Swiss Journal Economics and Statistics, 156 Article Number 7.

13. Fezzi, C., Fanghella, V. (2020). Real-Time Estimation of the Short-Run Impact of COVID-19 on Economic Activity Using Electricity Market Data. Environmental and Resource Economics, 76 (4), 885-900. 
14. Sheldon, G. (2020). Unemployment in Switzerland in the wake of the Covid-19 pandemic: an intertemporal perspective. Swiss Journal Economics and Statistics, 156, Article Number 8.

15. Dingel, J.I., Neiman, B. (2020). How many jobs can be done at home? Journal of Public Economics, 189, Article Number 104235.

16. Balmford B., Annan J.D., Hargreaves J. C., Altoe M., Bateman I.J. (2020). Cross-Country Comparisons of Covid-19: Policy, Politics and the Price of Life Environmental and Resource Economics, 76(4), 525-551

17. Ward, M. (2020). South Africa's COVID-19 lockdown dilemma. Emerald Emerging Markets Case Studies, 10(3), 1-10

18. Banks J., Karjalainen H., Propper C. (2020). Recessions and Health: The Long-Term Health Consequences of Responses to the Coronavirus. Fiscal Studies, 41(2), 337-344

19. Grigoriev, L.M, Pavlyushina, V.A., Muzychenko, E.E. (2020). The Fall into 2020 Recession... Voprosy Ekonomiki, 2, 5-29. 